\title{
SOME REFLECTIONS ON THE LATE DEVELOPMENT HYPOTHESIS
}

\section{Ronald Dore}

The industrial relations research is the first piece of research I have ever done which started, in proper text book fashion, from a set of hypotheses (a) about what the facts would prove to be, and (b) about why the situation should be what it was predicted to be. It is also the first piece of research in which $I$ have relied on colleagues to collect the data. Luckily, these two features are complementary. Everyone likes his hypotheses to come true, and hence considerable dangers of selective perception exist. It is an excellent corrective, therefore, if he has collaborators who, while sharing a strong common in terest in getting to the bottom of things and finding out 'how it works', would prefer on balance that the hypotheses should prove to be wrong!

It has turned out, as Maureen Mackintosh says in her paper, to be a contentious area. Generally, I have found that it is not only neo-classical economists who dislike my hypotheses (after all the possibility of devising genuinely exciting models of labour market functioning if wage employment is as 'corporatist' as I suggest is much reduced even if one does retreat to the curious term 'internal market' to make the best of a bad job), but also those who would consider themselves as 'on the left'. The alliance, of course; is not at all unusual; both neo-classicals and the hard-nosed left share the assumption that for all their blatherings about love and duty and status and loyalty what really makes men and women tick is hard material interest. But I think that is not all there is to it. There are, I think, several other reasons why people of left-wing views should consider my hypotheses distasteful: because those hypotheses seem to assume the viability of a kind of corporatist pattern in industry in which workers are willing to co-operate with managers even though they are placed in an explicitly subordinate position; because they consequently rule out the likelihood of a rising tide of class consciousness leading to revolutionary social change; because they place little importance on the dependency relationship and the question of domestic or foreign ownership in determining patterns of industrial employment; or because contrariwise, the hypotheses assume that the early developers remain 
the chief innovators and late developers get most of their ideas and institutions by imitation rather than innovation.

Perhaps another reason was that in postulating the mechanisms which explain the expected pattern, the hypotheses gave (extrapolating from what I knew of Japanese history) a very large role to the initiative of managers. One thing that does emerge pretty clearly from our research in all three countries is that any assumption that employers in late developing countries would generally go through the same process of creating a Japanese-type system as their Japanese counterparts had in the 1910s and 1920s, is wrong. (There is perhaps one exception: the Mexican group which owns the brewery and steel mill described by Miguel Sanchez Padron. It showed much the same management-led development as Japanese firms - but almost contemporaneously; it is a group with a long history).

Thus it is, as both Maureen Mackintosh and Miguel Sanchez Padron point out, that some of the features which we expected to find are there but not for the reasons which were originally postulated. The protected status of permanent workers, the practices of internal promotion, are imposed by the state in Senegal, and by the pressure of unions backed by the law in Mexico.

This points up one very important feature of 'later' late development: the fact that the mechanisms which form a country's internal institutions - e.g. of the labour market - are increasingly world-wide in extent. The practices of the 'Japanese system' were gradually institutionalized in Japan as the result of the initiatives of a number of individual managements (and in the post-war period individual unions) gradually becoming diffused through the country by the forces of imitation and competition and only subsequently being reinforced by any legal changes. Foreign countries played only a small part in this, providing some models - the management policies of Krupp and National Cash Register, for instance - and providing warnings of the class conflict which lay ahead if some thought was not taken to avoid it. The workers in Senegal, however, get some of the same institutions because France, re-constructing its social institutions in the post-war period, (unlike England which had no such occasion for deliberate social reconstruction and is still agonizing over the process ten years after the appointment of the Donovan Commission) could embody in 
authoritative law some of the accumulated demands of French unions which 'enlightened' employers were prepared to concede, and because these laws were then diffused to the colonies - partly thanks to the demands of colonial unions which would settle for nothing less in the way of rights than those which had become the norm in the metropolitan country.

So the process of institutionalization of employment systems becomes a very complex one which cannot be traced only within the boundaries of a single country - even one as large and in many ways culturally self-sufficient as Mexico. One of the more interesting mechanisms overlooked in the original hypotheses is the way in which external examples raise the expectations of workers, give them the confidence to demand concessions as of right, which sense of having justifiable demands employers then have to reckon with. In all three countries, for example, it appears that a man who has been in the same job category at the same wage rate for many years without promotion or a personal increment is likely to feel hard done by - a factor which was both a consequence of the increasing institutionalization of internal promotion systems and a force which is in some cases helping to change job structures, causing them to be designed to provide promotion opportunities, as Miguel Sanchez Padron's example of the parallel promotion chains in the tool-room and the paint-shop exemplify.

Senegal, with its cultural gulf between the predominantly French management and Senegalese workers, shows little of the ideological concomitants of the Japanese employment pattern - the deliberate fostering of 'loyalty' to the firm, the stress of an ethic of craftsmanship and service, the fostering of a sense of community. Such attempts are more common in Mexico, but on the whole of no great consequence in any of the three countries. Low labour turnover and "permanent employment' within the limits that it exists, (the greater mobility of highly skilled workers in Mexico and even more in Senegal as shown in these two papers are important exceptions to the general picture) are a function rather of the shortage of jobs and of the fact that anyone who is lucky enough to have one sticks to it. The mere fact of long-term, if not lifetime, employment, does bring with it a number of other features, however. Many of the welfare provisions which firms provide, in Mexico and Sri Lanka as well as in Senegal, make sense from the 
employer's point of view only on the assumption that his present workers are still likely for the most part to be with him in five years' time; so also are their training programmes.

There is certainly not much evidence in Mexico or Sri Lanka, either of incremental pay scales, or predictable promotion opportunities, being deliberately provided by employers as a means of retaining skilled workers in whose training they have invested. (The manager of the Mexican firm whose 'company philosophy' Miguel Sanchez Padron quotes is something of an exception). Where incremental scales are found - as they are very widely in Sri Lanka, for instance - they are the result either of the extension to industry of the practices of a colonial bureaucracy, or of concessions gained by unions. One of the reasons why this practice developed in Japan was that factory owners in the upper tier of the dual structure could hire the young school leavers who were clamouring to get into their factories, at extremely low rates of pay which they could then raise to a bare family wage by the time the young men were ready to get married. This required two things missing in our three contemporary countries:

(a) general acceptance of the principle of a person-related as opposed to job-related wages, and

(b) ability of employers to drive down the wages of new recruits to the lowest rate which would assure supply.

The first condition is hardly fulfilled: the 'equal pay for equal work' principle is probably a good deal more firmly entrenched in our three countries than in Japan fifty years ago. But there are some exceptions, as is shown for both countries, so that perhaps the second condition is more important. Where minimum wage legislation is enforced - as in the large-firm sector in Mexico, for example - employers cannot offer their new recruits the low market rates which prevail in the informal small scale sector. The two factors are inter-related; if employers cannot gain the advantage of low initial rates of pay, they have less incentive to try to push to a person-related, rather than a job-related wage.

Of all the policy issues involved in this research, this one concerning the principles which should govern wage payments - whether they should be on an exclusively rate-for-the-job basis or whether, like university salaries in this country, they should be on a person-related 
seniority/merit basis - is one of the most intriguing. It involves abstract principles of justice, as well as theories of work motivation, and has wide implications for social and political consciousness as well as for productivity. And the difficult thing is that there is no clear one-to-one relation between institutional form and social consequence. Managers in state corporations in Sri Lanka have conditions of security and predictable career prospects rather similar to those which in Japan seem to be preconditions for the cohesion and co-operativeness in working relationships which Japanese managers seem to display. But in Sri Lanka's different ideological setting the consequences are rather different. There seems to be a good deal of mutual suspicion, much jockeying for position, a deliberate use of competition for stimulating effort, little disposition to take initiatives which expose one's flank or involve one in extra work. The lights in managers' offices do not so of ten burn late into the night as they do in Japan. These differences in the ideological and cultural setting, in the definitions of the purposes of life and work which people bring in to their offices and factories, are immensely important.

The whole thrust of my industrial relations research since I began a comparison between Britain and Japan eight years ago has been to reduce the importance attributable in historical explanation to the Paretian 'residues', to show how some of the features of Japanese or Mexican industrial relations popularly ascribed to 'national character' or 'cultural tradition' could instead be accounted for in a simpler universalistic framework of explanation - as the rational material-interest-maximizing responses of people (not Japanese or Mexicans) to the logic of their situation.

But when one had done all that, one is still left, as Maureen Mackintosh makes clear in her last paragraphs, with a wide range of national differences which remain unaccounted for and which it seems only reasonable to ascribe to cultural differences. At that point the sociologist tends to fudge, to look the other way, or at best to refer to the importance of 'national character' or 'cultural traditions' (I have done it myself, sheepishly putting the words in quotes by way of apology for mentioning the subject) and leave it at that. There are at least four reasons for this: because this is an immensely difficult field to handle in any genuinely scientific manner; because, for absurd reasons 
of academic tribalism, most sociologists are scared of being accused of 'psychologism' - and these problems do require an overtly psychological approach; and thirdly, because discussions of 'national character', 'modal personality' or 'cultural tradition' smack of racism; and who wants to be called a racist?

The fourth reason is more respectable: because national character is not something anybody can do much about, whereas, say, the institutional structure of labour legisation, or relations of cultural dependency, are amenable to social engineering. There is indeed a case for concentrating one's research on the aspects of developing country situations about which something can be done. But to do so does not require that one ignores or denies the importance of these other cultural factors in determining outcomes. If one does, one ends up with a partial, unconvincing and probably naively optimistic view of the situation. One also offends the sense of plausibility of, and loses the chance to communicate with, the 'practical men' who conduct their daily business on the common-sense assumption that these differences of national character are of enormous importance. And so, naturally, the practical men turn to the writers who do acknowledge the factors that seem to them important - to the Peter Bauers of this world, who are happy to talk about national character because they do not mind being called racists.

Our industrial relations research has, I think, "pushed back the frontiers of the residues' just a little bit, shown some of the common features of industrial relations systems in LDCs which can be explained in terms of similar situational logics and simple interest-maximizing motives though not necessarily, by any means, the features that the hypotheses suggested. And that, I suppose, is a contribution - as Miguel Sanchez Padron suggests in his last paragraph, if we do nothing more than prompt people to think through the manifold implications of adapting rich country labour market and personnel management institutions, designed for situations in which the average length of an employment relation is $2 \frac{1}{2}$ years, to situations in which it is likely to be 15 or 25 years, we shall have achieved something. But I wonder whether just pushing back the frontiers of the residues is enough; whether we should not, more explicitly, have sallied forth among the residues and studied them? 